Research Article

\title{
Sifat Mekanis pada Kompon Karet Alam Variasi Campuran Serbuk Ban Bekas untuk Aplikasi Bantalan Mesin
}

\author{
Agus Suharto ${ }^{1}$ dan Joko Sedyono ${ }^{2}$ \\ ${ }^{1}$ Teknik Mesin, Universitas Muhammadiyah Ponorogo, Indonesia \\ ${ }^{2}$ Teknik Mesin, Universitas Muhammadiyah Surakarta, Indonesia \\ Email:Skarlawoe@gmail.com, Joko.sedyono@ums.ac.id
}

Corespondensi author :Skarlawoe@gmail.com

Article History:

Online first:

18 January 2021

Keywords: Vulkanizate, Tensile Strength \& Elongation at break,Hardness, Tear strength
Kata Kunci: Kompon Karet, Tegangan \& Perpanjangan putus, Kekerasan, Kekuatan sobek

\begin{abstract}
Rubber is a good material used for engine mounting because it has good elastic and damping properties. To obtain good mechanical and damping properties, fillers can be added such as carbon black, nylon powder and silica. In this study used used tire crumb as filler material. With the method of adding used tire powder $0 \mathrm{phr}, 6 \mathrm{phr}, 12 \mathrm{phr}, 18 \mathrm{phr}$ sequentially on natural rubber compound $A, B, C$, and D. Rubber compounds made in this process are tested to determine the mechanical properties and Dumping vibrations. Tests carried out namely, strength and elongation at break, hardness, tearing strength, flex crack resistance and dumping vibration ( ability to reduce acceleration of vibration propagation ). The test results show a decrease in the strength of $21.7 \mathrm{~N} / \mathrm{mm}^{2}, 20.9 \mathrm{~N} / \mathrm{mm}^{2}, 20.3 \mathrm{~N} / \mathrm{mm}^{2}, 20.5 \mathrm{~N} / \mathrm{mm}^{2}$, and also at the elongation at break test with an average of $430 \%$, $415 \%, 423 \%, 425 \%$. Sequentially on A, B, C and D vulcanizates. Trends of hardness test chart to increase 61 Shore A, 63 Shore A, 64 Shore A and 65 Shore A, while the tear strength also shows an increase and decrease with an average yield of $12.5 \mathrm{~N} / \mathrm{mm}^{2}, 12.6$ $\mathrm{N} / \mathrm{mm}^{2}, 11.3 \mathrm{~N} / \mathrm{mm}^{2}, 13.3 \mathrm{~N} / \mathrm{mm}^{2}$ on $A, B, C$ and $D$ vulcanizates.
\end{abstract}

\section{ABSTRAK}

Karet merupakan material yang bagus digunakan untuk bantalan mesin karena mempunyai sifat elastis dan peredaman yang baik. Untuk memperoleh sifat mekanis dan peredaman yang baik bisa ditambahkan bahan pengisi seperti contoh Karbon hitam, serbuk nylon dan silika. Pada penelitian kali ini digunakan serbuk ban bekas sebagai bahan pengisi. Dengan metode penambahan serbuk ban bekas $0 \mathrm{phr}, 6 \mathrm{phr}, 12 \mathrm{phr}, 18 \mathrm{phr}$ secara berurutan pada kompon karet alam A, B, C, dan D. Kompon karet yang dibuat pada proses ini dilakukan pengujian untuk mengetahui sifat mekanik dan peredaman terhadap getaran. Pengujian yang 
dilakukan yaitu, tegangan putus dan perpanjangan putus, kekerasan, kekuatan sobek. Hasil pengujian menunjukkan penurunan pada tegangan putus yaitu $21.7 \mathrm{~N} / \mathrm{mm}^{2}, 20.9 \mathrm{~N} / \mathrm{mm}^{2}$, $20.3 \mathrm{~N} / \mathrm{mm}^{2}, 20.5 \mathrm{~N} / \mathrm{mm}^{2}$, dan juga pada uji perpanjangan putus rata-rata $430 \%, 415 \%, 423 \%, 425 \%$. Secara berurutan pada vulkanisat A,B,C, dan D. Untuk grafik uji kekerasan cenderung mengalami kenaikan yaitu 61 Shore A, 63 Shore A, 64 Shore A dan 65 Shore A, sedangkan pada kekuatan sobek juga menunjukkan kenaikan dan penurunan dengan hasil rata-rata 12.5 $\mathrm{N} / \mathrm{mm}^{2}, 12.6 \mathrm{~N} / \mathrm{mm}^{2}, 11.3 \mathrm{~N} / \mathrm{mm}^{2}, 13.3 \mathrm{~N} / \mathrm{mm}^{2}$ pada vulkanisat A, B, C dan D.

\section{PENDAHULUAN}

Karet alam merupakan salah satu hasil alam terbesar Indonesia dan merupakan komoditi ekspor, namun pemakaiannya masih banyak diekspor dalam keadaan mentah daripada dalam keadaan produk jadi. Keadaan ini disebabkan karena biaya dan sumber daya manusianya yang kurang memadai, sehingga mutu dari barang karet yang dibuat masih kalah jauh dibanding dengan negara-negara lain[7],[15]. Oleh karena itu kita dituntut untuk mengoptimalkan sumber daya alam yang berupa karet alam dengan sebaik-baiknya, supaya dapat menghasilkan dan meningkatkan devisa Negara. Hal ini dapat direalisasikan melalui riset atau penelitian mengenai sifat dan karakteristik karet tersebut, serta bagaimana cara mengolahnya, sehingga nantinya dapat meningkatkan nilai tambah barang tersebut.

Karet alam mempunyai sifat elastis, fleksibel serta peredaman yang baik. Keuntungan inilah yang bisa dimanfaatkan untuk membuat produk bantalan, diantaranya bantalan dudukan mesin kendaraan bermotor (engine mounting), karet bantalan rumah tahan gempa ( base isolation system ) dan sebagainya[13],[16]. Berbagai macam usaha telah dilakukan untuk mencari kelebihan material karet sesuai dengan aplikasinya [1],[3]. Tentu saja usaha-usaha ini melewati proses pengujian berdasarkan standar yang ada untuk mengetahui kelayakannya.

Sejauh ini telah dilakukan riset atau penelitian dalam bentuk penambahan serbuk nylon sebagai bahan pengisi. Tetapi pada penelitian kali ini kami menggunakan serbuk ban bekas sebagai bahan pengisi dan diharapkan dengan penambahan serbuk ban ini dapat meningkatkan sifat peredamannya, menambah kekuatan tarik, kekerasan, kekuatan sobek, ketahanan retak lentur [4]. Kemudian dengan adanya pengaruh yang ditimbulkan oleh penambahan serbuk ban pada modifiaksi formula kompon karet alam dapat digunakan sebagai referensi untuk membuat formula karet bantalan yang sesuai dengan aplikasinya.

Kompon karet adalah campuran karet mentah dengan bahan-bahan kimia yang belum divulkanisasi. Proses pembuatan kompon adalah proses pencampuran antara karet mentah dengan bahan- bahan kimia karet ( bahan aditif ) [11],[16]. Karet mentah dapat berupa karet alam maupun karet sintetis yang mempunyai sifat berbeda- beda satu dengan yang lainnya[14]. Pemilihan jenis karet yang akan digunakan dalam pengolahan kompon karet akan menetukan sifat-sifat barang jadi yang akan dihasilkan. Bahan kimia yang digunakan untuk meningkatkan sifat fisis karet dalam pembuatan kompon adalah bahan filler ( bahan pengisi ), anti oksidan, bahan activator dan bahan kimia lainnya [1],[12]. Dalam penelitian ini dibutuhkan variasi komposisi kompon yang di gesekan dengan lintasan semen untuk memperoleh hasil yang diinginkan. 


\section{METODE PENELITIAN}

Penelitian pembuatan sampel uji kompon karet alam dengan variasi campuran serbuk ban bekas serta pengujian Tegangan dan regangan putus, uji kekerasan, kekuatan sobek di Pusat Penelitian Karet Bogor.

Penentuan Formula Kompon Karet

Tabel 1. Formula kompon karet alam dalam satuan gram

\begin{tabular}{lllllll}
\hline \multirow{2}{*}{ No } & Bahan-bahan & Bahan & \multicolumn{4}{c}{ Variasi kompon (phr) } \\
\cline { 3 - 7 } & & A & B & C & D \\
\hline 1 & Karet Alam & RSS & 500 & 500 & 500 & 500 \\
\hline 2 & Bahan Penggiat & ZnO & 25 & 25 & 25 & 25 \\
\hline 3 & Bahan Penggiat & Stearad acid & 10 & 10 & 10 & 10 \\
\hline 4 & Anti Ozonan & 6PPD & 5 & 5 & 5 & 5 \\
\hline 5 & Anti Oksidan & TMQ & 5 & 5 & 5 & 5 \\
\hline 6 & Bahan Pengisi & Carbon Black N330 & 300 & 300 & 300 & 300 \\
& aktif & & & & & \\
\hline 7 & Bahan Pelunak & Aromatic Oil & 25 & 25 & 25 & 25 \\
\hline 8 & Bahan & Sulfur & 12,5 & 12,5 & 12,5 & 12,5 \\
& Pemvulkanis & & 3,25 & 3,25 & 3,25 & 3,25 \\
\hline 9 & Bahan Pencepat & MBTS & 1,25 & 1,25 & 1,25 & 1,25 \\
\hline 10 & Bahan Pencepat & DPG & 5 & 5 & 5 & 5 \\
\hline 11 & Anti Ozonan & Parafin Wax & 0 & 30 & 60 & 90 \\
\hline 12 & Bahan Pengisi & Serbuk Ban & & &
\end{tabular}

\section{Pembuatan Potongan Uji}

Pembuatan potongan uji menggunakan alat Dies Dumbell, Potongan uji dibentuk dari lembaran plat hasil vulkanisasi kompon karet dengan menggunakan mesin hidraulik press pada temperature tertentu. Material potongan uji yang telah dibentuk tidak langsung dapat dilakukan pengujian.

Lembaran hasil vulkanisasi tersebut harus disimpan selama \pm 24 jam dahulu dihitung dari selesai pembuatan, karena sifat fisik karet yang tervulkanisasi berubah terus selama penyimpanan. Perubahan terbesar sifat tersebut pada masa 24 jam setelah vulkanisasi, dan oleh karena itu selama masa 24 jam setelah vulkanisasi tidak boleh langsung dilakukan pengujian.

\section{Proses Pengujian}

Pengujian Tegangan Putus ( Tensile Strenght) dan Perpanjangan Putus ( Elongation at break ). Pengujian harus dilakukan pada suhu dan kelembaban udara tertentu, karena suhu dan kelembaban berpengaruh pada sifat fisik karet. 
Berbentuk dumble (dayung) sebanyak 4 buah untuk masing-masing formula

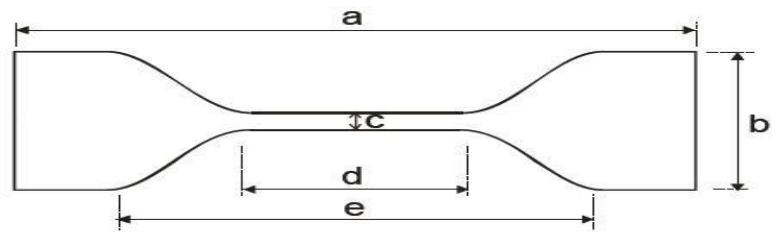

Gambar 1. Spesimen uji Tegangan Putus dan Perpanjangan putus

Keterangan :
a. $\quad:(75 \pm 1) \mathrm{mm}$
b. : $(25 \pm 1) \mathrm{mm}$
c. $\quad:(3 \pm 0.1) \mathrm{mm}$
d. $:(25 \pm 0.5) \mathrm{mm}$
e. $\quad:(50 \pm 1) \mathrm{mm}$

Tebal cuplikan : maksimum $2 \mathrm{~mm}$

\section{Pengujian Kekerasan}

Pengujian kekerasan adalah daya tahan bahan terhadap goresan atau penetrasi pada permukaanya. Definisi yang lain adalah ukuran ketahanan bahan terhadap deformasi plastis.

Tiga jenis umum mengenai ukuran kekerasan yang tergantung cara pengujian, yaitu kekerasan goresan (scrath hardness), kekerasan lekukan (indentation hardness), dan kekerasan pantulan ( rebound hardness ) atau kekerasan dinamik (dynamic hardnerss).

\section{Pengujian Kekuatan Sobek}

Ketahanan sobek adalah besarnya tenaga yang dibutuhkan untuk menarik potongan uji yang telah diberi sobekan kecil dan ditarik sampai putus. Berbentuk pelat vulkanisat dengan panjang $6 \mathrm{~cm}$, lebar $1 \mathrm{~cm}$, tebal $\pm 2 \mathrm{~mm}$, sebanayk 6 buah dan ditengah tengahnya ,tegak lurus pada sumbu panjang terdapat keratan selebar $\pm 4,5 \mathrm{~mm}$

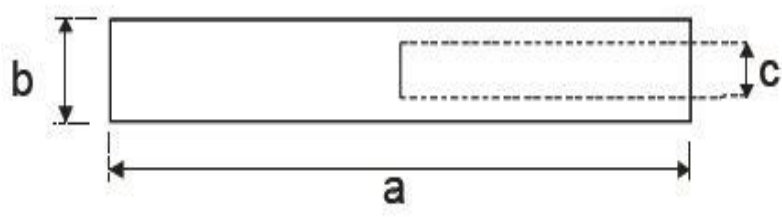

Gambar 2. Spesimen uji kekuatan sobek

Keterangan :

a. $\quad: 60 \mathrm{~mm}$

b. $\quad: 9.0 \pm 0.1 \mathrm{~mm}$

c. $\quad: 5.0 \pm 0.1 \mathrm{~mm}$

Tebal cuplikan : maksimum $2 \mathrm{~mm}$

Ukur bagian yang tidak tersobekan ini dengan mikrometer geser. Dan untuk 5 buah yang lainnya pasang potongan uji pada alat tensometer dengan posisi simetris, tekan Go pada kontrol panel, kemudian setelah potongan uji putus alat akan kembali secara otomatis ke posisi semula, sementara itu catat tenaga yang dihasilakan $(\mathrm{N}$ ) pada control panel. 


\section{HASIL DAN DISKUSI}

\section{Pembahasan Tegangan dan Perpanjangan Putus}

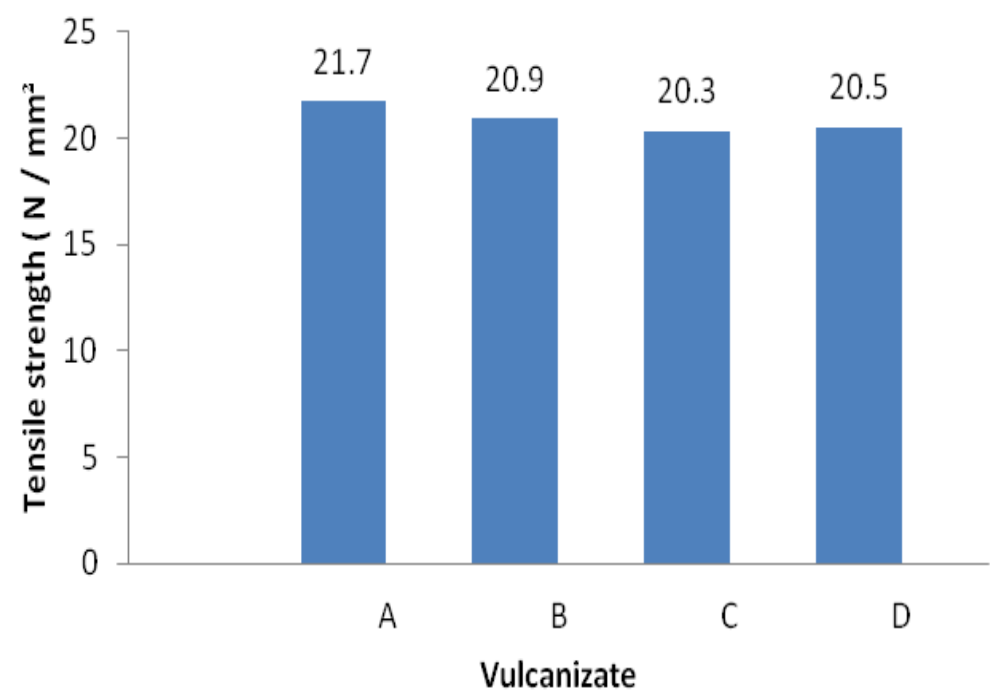

Gambar 3. Tegangan Putus

Tegangan putus suatu kompon karet atau vulkanisat menyatakan kemampuan untuk menerima gaya tarik yang bekerja di dalamnya mencapai nilai optimal ( tertinggi / terbesar ) sebelum putus. Tegangan putus sangat dipengaruhi oleh jumlah dan jenis bahan pengisi yang ditambahkan ke dalam karet, baik golongan pengisi aktif maupun bahan pengisi non aktif[3],[5],[9]. Bahan pengisi aktif bisa menambah kekerasan, ketahanan sobek, ketahanan kikis, perpanjangan putus dan tegangan putus yang tinggi pada kompon karet[6],[8]. Sedangkan penambahan bahan pengisi tidak aktif hanya akan menambah kekerasan dan kekakuan pada kompon karet, tetapi tegangan putusnya berkurang atau menurun[7],[14]. Pada penelitian ini digunakan formula kompon karet alam dengan komposisi HAF Black N330 sebagai bahan pengisi aktif dengan nilai $60 \mathrm{phr}$. Dengan penambahan bahan pengisi aktif tersebut, ternyata memberikan kontribusi nilai tegangan putus yang tergolong tinggi[2][7]. Hal tersebut dapat dilihat pada hasil penelitian variasi kompon A yang mempunyai nilai $21.7 \mathrm{~N} / \mathrm{mm}^{2}$, bila dibandingkan dengan variasi yang menggunakan serbuk ban yaitu variasi $\mathrm{B}, \mathrm{C}$ dan $\mathrm{D}$ masingmasing mempunyai nilai $6 \mathrm{phr}, 12 \mathrm{phr}$ dan $18 \mathrm{phr}$. Ternyata panambahan serbuk ban ke dalam karet menurunkan sifat tegangan putusnya, yaitu dari nilai $21.7 \mathrm{~N} / \mathrm{mm}^{2}, 20.9 \mathrm{~N} / \mathrm{mm}^{2}, 20.3$ $\mathrm{N} / \mathrm{mm}^{2}$ sampai $20.5 \mathrm{~N} / \mathrm{mm}^{2}$ pada vulkanisat A, B, C dan D. Sesuai dengan teori yang menyatakan bahwa bahan pengsisi non aktif malah menurunkan sifat-sifat yang lain seperti tegangan putus dan perpanjangan putus[6],[10]. 


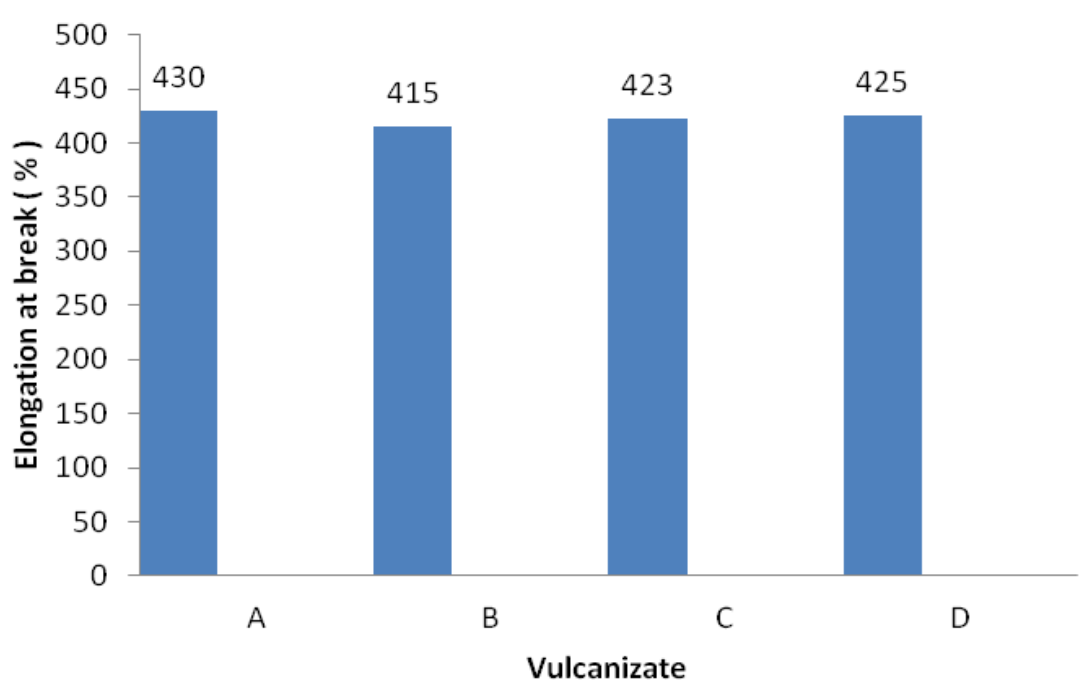

Gambar 4. Perpanjangan putus

Sedangkan data perpanjangan putusnya yaitu dari nilai $430 \%, 415 \%, 423 \%$ sampai $425 \%$ pada vulkanisat A, B, C dan D. Dari analisa varian data hasil uji perpanjangan putus menunjukkan pengaruh yang cukup signifikan dari penambahan serbuk ban terhadap peningkatan jumlah nilai phr. Sehingga sifat perpanjangan putus mengalami penurunan. Hal ini menyatakan bahwa semakin besar nilai phr bahan pengisi non aktif (serbuk ban) yang ditambahkan ke dalam suatu vulkanisat, maka kemampuan untuk bertambah panjang semakin menurun[6],[12].

\section{Pembahasan Kekerasan}

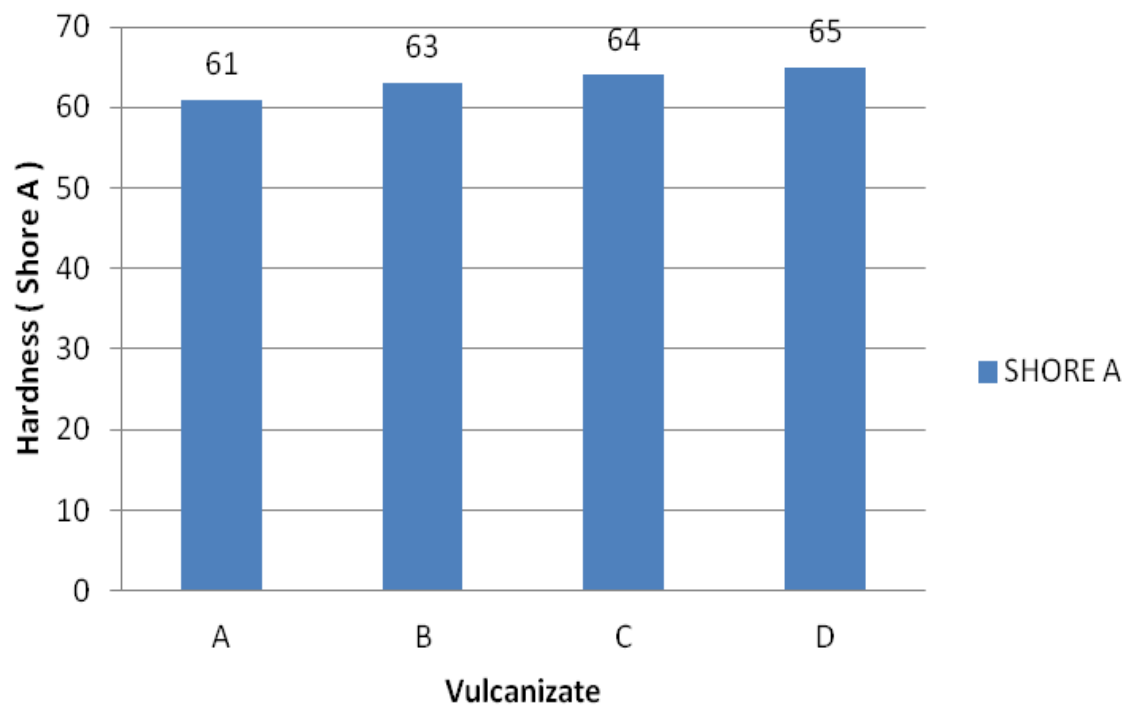

Gambar 5. Kekerasan

Dari analisa varian data hasil uji kekerasan menunjukkan pengaruh peningkatan kekerasan akibat dari penambahan serbuk ban terhadap naiknya jumlah nilai phr bahan pengisi, sehingga sifat kekerasan cenderung meningkat.. Hal ini menyatakan bahwa semakin besar nilai phr bahan pengisi non aktif (serbuk ban) yang ditambahkan ke dalam suatu vulkanisat, maka 
kemampuan sifat kekerasan dan kekakuan semakin naik [14],[15].

\section{Pembahasan Kekuatan Sobek}

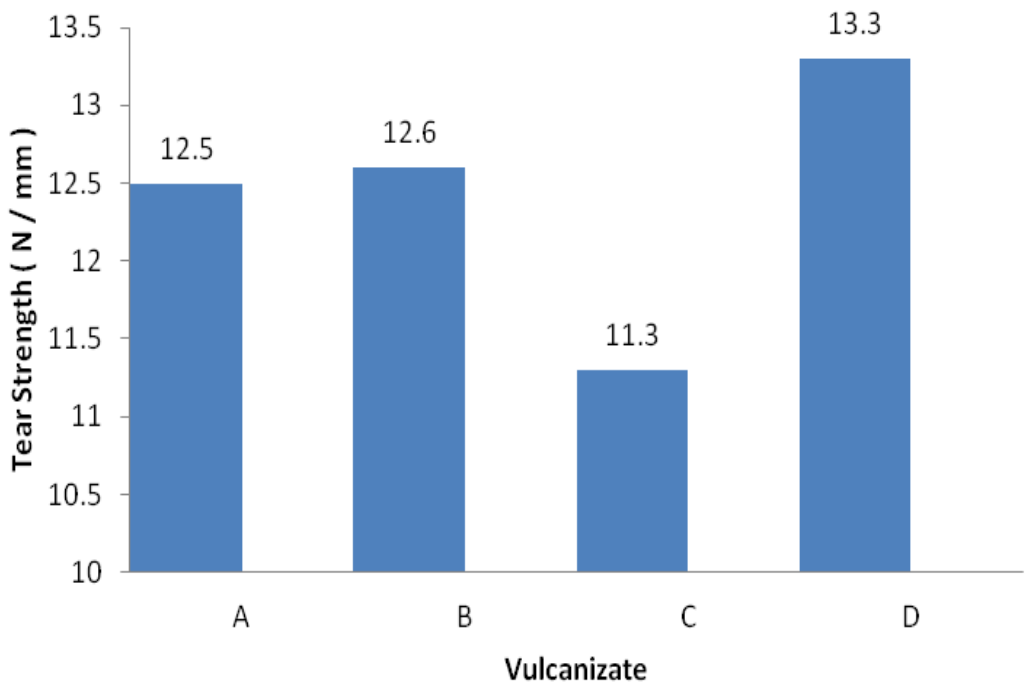

Gambar 6. Kekuatan Sobek

Kekuatan sobek merupakan besarnya tenaga yang dibutuhkan untuk menarik potongan uji yang telah diberi sobekan kecil dan ditarik sampai putus. Pada penelitian kali ini ternyata penambahan serbuk ban bekas pada formula kompon karet Alam cukup berpengaruh meningkatkan ketahanan sobeknya [11],[17]. Nilai kekerasan dan kekuatan sobek juga sangat berkaitan karena semakin banyak komposisi bahan pengisi ( serbuk ban bekas ) terlihat semakin naik kekerasanya, sehingga juga berakibat meningkatkan kekuatan sobeknya. Dari grafik diatas terlihat ada kecenderungan nilai kekuatan sobek naik pada sampel sampel B dan sampel D, namun juga ada penurunan nilai kekuatan sobek pada sampel C. Kenaikan kekuatan sobek ini disebabkan karena semakin banyak bahan pengisi serbuk ban bekas maka vulkanisat semakin keras dan cenderung semakin sulit untuk disobek [16],[17].

\section{KESIMPULAN}

Dari data yang sudah dianalisa ternyata penambahan serbuk ban bekas cukup berpengaruh terhadap sifat tegangan putus dan perpanjangan putus pada suatu vulkanisat yaitu menurunkan nilainya. Penambahan serbuk ban pada kompon karet alam terlihat meningkatkan kekerasanya. Sedangkan pada penambahan serbuk ban pada kompon karet alam berpengaruh meningkatkan ketahanan sobek meskipun tidak terlalu signifikan karena juga ada penurunan pada salah satu sampel uji.

\section{DAFTAR PUSTAKA}

[1] Darina Ondrusov, Slavomira Domcekova, Mariana Pajtasova, Andrej Dubec, Zuzana Micicova, Beata Pecusova, 2017. Alternative filler based on the waste from glass production and its effect on the rubber properties. Alexander Dubcek University of Trencin. https://doi.org/10.1016/ j.proeng. 2017.02.246 
[2] Nagornaya M.N, Razdyakonova G.I.b, Khodakova S.Ya.a, 2016. The effect of functional groups of carbon black on rubber properties. Omsk State TechnicalUniversity, Mira Pr., Omsk. Russian Federation. https:// doi.org/ 10.1016/j.proeng.2016.07.656

[3] Mariana Pajtasova, Zuzana Micicova, Darina Ondrusova, Beáta Pecusova, Andrea Feriancova, Lukas Raník, Slavomíra Domcekova, 2016. Study of properties of fillers based on natural bentonite and their effect on the rubber compounds. Alexander Dubcek University of Trencín. doi:10.1016/j.proeng.2017.02.247

[4] Nicolas Rochea., Laurent Perierb, 2013. Influence of elastomers formulation on fatigue crack growth properties. Chemin des Ormeaux, 69578 Limonest, France. doi: 10.1016/ j. proeng. 2013.12.124

[5] Mihara, S. (2009). Reactive processing of silica-reinforced tire rubber: new insight into the time and temperature dependence of silica rubber interaction. Enschede: University of Twente. https:// doi.org/10.3990/ 1.9789036528399

[6] Agus Maryoto, Nor Intang Setyo Hermanto, Yanuar Haryanto, Sugeng Waluyo, Nur Alvi Anisa, 2014.Influence of prestressed force in the waste tire reinforced concrete. Jenderal Soedirman University. Purbalingga,Jawa Tengah, 53371, Indonesia. doi:10.1016/j.proeng.2015.11.088

[7] Hanafi Ismail, R. Nordin \& Ahmad Md. Noor, 2007. The Comparison Properties Of Recycle Rubber Powder, Carbon Black, And Calcium Carbonate Filled Natural Rubber Compounds. School of chemistry Universiti of Sains Malaysia 11800, Minden, Penang, Malaysia. https://doi.org/10.1081/PPT-120014392

[8] Yi Fang, Maosheng Zhan, Ying Wang, 2001. The status of recycling of waste rubber. Department of Materials Sciences and Engineering, Beijing University of Aeronautics And Astronautics, Beijing 100083, PR China. https://doi.org/10.1016/S0261- 3069 (00)00052-2

[9] B.Maridass, B.R.Gupta,2004. Performance optimization of a counter rotating twin screw extruder for recycling natural rubber vulcanizates using response surface methodology. Rubber Technology Centre, Indian Institute of Technology, Kharagpur 721302, India https:// doi.org/ 10.1016/j.polymertesting.2003.10.005

[10] A. A. Yehia, M. A. Mull, M. N. Ismail, Y. A. Hefny, E. M. Abdel-Bary.2004. Effect Of chemically modified waste rubber powder as a filler in natural rubber vulcanizates. Chemistry Department, Faculty of Science, Mansoura University Egypt. https://doi.org/10.1002/app.20349

[11] J. I. Kim, S. H. Ryu, Y. W. Chang.2000.Mechanical and dynamic mechanical properties of wasterubber powder/HDPE composite. Department of Chemical Engineering, Han Yang University,Kyunggi-Do, South Korea. https://doi.org/10.1002/1097- 4628(20000919)77

[12] Jin Kuk Kim; R. P. Burford.,1998. Study on Powder Utilization of Waste Tires as a Filler in RubberCompounding. Department of Polymer Science \& Engineering,Research Institute of Industrial Technology, Gyeongsang National University, Chinju, Korea 660-701 https:// doi.org/ $10.5254 / 1.3538508$

[13] H. Ismail N. F. Omar N. Othman,2011. Effect of carbon black loading on curing Characteristics and mechanical properties of waste tyre dust/carbon black hybrid filler filled natural rubber compounds. School of Materials and Mineral Resources Engineering, Universiti Sains Malaysia, https:// doi.org/10.1002/app.

[14] Wang Zefeng, Kang Yong, Wang Zhao, and Cheng Yi, 2017. Recycling waste tire rubber by water jet pulverization powder characteristics and reinforcing performance in natural rubber composites.,Hubei Key Laboratory Of Water Jet Theory and New Technology, Wuhan University, Wuhan 430072,China. DOI:https://doi.org/10.1515/polyeng-2016-0383.

[15] VPFK Alam, BL Sanyoto, N Husodo. 2009. Penerapan Pembuatan Karet Bantalan ( Produk Engine Mounting ) Dengan Bahan Pengisi Serbuk Vulkanisat Pada Formula Karet Alam. SNTTM VIII. Semarang. prosiding.bkstm.org 
Vol.1, No.1, Januari 2021, pp.24-32

e-ISSN: 2774-8006 | p-ISSN: 2774-8278

[16] Tumanggor O. 2014. Karet Lembaran Yang Terbuat Dari Campuran Serbuk Ban Bekas Dan Karet Alam Yang Disetarakan Dengan SIR -20 Untuk Pembuatan Bahan Sol Sepatu Olah Raga. Universitas Sumatera Utara. Medan. repository.usu.ac.id/ handle/123456789/66335

[17] Fajar Andi S, Savetlana S 2016. Pengaruh Karbon Hitam Terhadap Sifat Uji Tarik Komposit Karet Alam Dengan Pencampuran Metode Manual. Fakultas Teknik Universitas Lampung. 